\title{
Family-School (Dis)Engagement: Understanding What It Is, What It's Not, and What to Do About It
}

\author{
MICHELANN PARR \\ Nipissing University \\ MARIANNE VANDER DUSSEN \\ Nipissing University
}

\begin{abstract}
This paper traces the journey of a community of schools, bound together by a geographical radius that sees some students travelling one hour each direction, as they attempt to interrupt institutional discourses and question the assumptions that underlie family-school engagement practices through collaborative inquiry and community-based research. We offer reconsideration of family (dis)engagement, and a set of principles to guide familyschool engagement that recognizes the diversity of the relationship, and the need for both families and schools to meet each other where they are, repositioning both parties as partnered, harmonic voices in the education of children.
\end{abstract}

\section{Family (Dis)Engagement: Exploring the Myth}

School-initiated family engagement typically aims to improve the family-school connection, keep families informed, and help families understand what it is that schools do on a day-to-day basis. Newsletters, blogs, school calendars, notes home, and curricular initiatives/workshops fall within this category and are reflective of the dominant literacies of reading and writing. School-based initiatives, of this nature, respond to questions such as, What do families need to know and do in order to help their children to be successful? or, How can we make families more supportive of their children's academic learning? This type of thinking perpetuates a schools know best narrative, suggesting that families may not be doing enough or that they need to more closely align with school practice, which often leads to further misperception and/or perceived power imbalance, which for many, further alienates instead of including (McKenna \& Millen, 2013, Pushor, 2011) and may actually serve to disengage parents.

As a professor in the faculty of education and a teacher in her first year of teaching, we must admit that at one time or another in our careers, we were likely guilty of perpetuating this narrative (Auerbach, 1989; McKenna \& Millen, 2013; Moll, Amanti, Neff, \& González, 1992; Pushor, 2011, 2012; Ramirez, 2004). Perhaps we forgot to check our assumptions at the door, prejudging families, comparing one to another, and/or stacking them up against impossible expectations. Perhaps we stayed in the staffroom a little too long as deficit-based conversations were taking place, and as families were criticized for what they did or did not do by our colleagues, we did not step in or defend. Perhaps we assumed that families weren't interested when they didn't show up for school-based events, neglecting to consider life demands and commitments. Perhaps we sent home long lists of things for families to do to support learning, unknowingly sending a message that we felt 
families weren't doing enough. Perhaps we didn't make room for families and children to talk first, but instead privileged our own observations, thoughts, and interpretations. Perhaps we just didn't recognize the busyness of families and their quest to ensure that their children were well-balanced in out-of-school activities, and we allowed ourselves to be frustrated by incomplete or late homework, unanswered notes, or unreturned books. Perhaps, in failing to recognize families' diverse terms of engagement, we rendered them hard to reach (Day, 2013). Perhaps, in failing to recognize family's unique funds of knowledge and literacies, they weren't the ones that were hard to reach, but in fact we rendered our schools hard to reach (González \& Moll, 2005; Moll, Amanti, Neff, \& González, 1992).

Perhaps, unwittingly, in our thoughts, our assumptions, and our practices, we were guilty of sustaining a myth of parent (dis)engagement, a myth grounded in the notion that families needed to shape up and do more at home in order to help their children be successful in life and in learning, a myth that is reflective of dominant mainstream literacies and definitions of success. And perhaps it was this narrow conceptualization of familyschool engagement that marginalized and silenced some families, leaving them feeling that their children's learning was not a place they felt they belonged.

\section{Discovering Purpose, Shifting Perspectives}

As researchers engaged in this project, we wondered what would happen if our family-school teams shifted their focus from telling to listening, from directing to sharing, from responding to asking. We realized that there were specific questions that we needed to ask of both ourselves and our family-school teams: What is it that families already do to support their children's development and learning? What happens when we help familyschool communities to recognize families as the first, most powerful, and likely the most sustainable source, and context, for learning? We wondered whether such explorations could help us to move beyond a school knows best perspective to a working together, family and schools know best stance. Our purpose was not solely to initiate positive shifts in the relationship between family and school, but to spark a richer sense of belonging, trust, respect, communication, and comfort among families, schools, and students alike.

The project did not disappoint, and at the end of the day, the research produced not only long lists of what families already do to support their children's learning in and out of school, but also a framework that could guide future work with families, schools, even communities, one that was grounded in celebration of diversity, with all parties having a right to be who they are and where they are in mutually respectful ways. Exploring the (dis)engagement myth and better understanding both parents' and educators' wants, needs, roles, responsibilities, and experiences of both privilege and marginalization may serve to alleviate the disconnect experienced by many families and schools.

In Theory: Understanding Who We Are as Teachers, What We Believe, and Why

From the time we are born, we are apprenticed into life through family, and we are loved and cared for in many different ways. Almost from the beginning of their teaching careers, teachers are exposed to both positive and negative narratives and stereotypes of families: supportive, intrusive, overbearing, withdrawn, aggressive, etc. Some families view school as simply an extension of home and as a result, are reticent to let go of the learning that began in the home. Then again, some families expect that school will offer 
what home did not or cannot and the responsibility for learning is eagerly given to the school. Assumptions, both positive and negative, have the potential to colour a teacher's perspective of a family before they even have their first direct encounter; tales told by educators with previous experiences dealing with families can often prevent a fresh, biasfree relationship from ever having the opportunity to begin. And yes, sadly, the same is true of families' perspectives of teachers. Understanding of what it means to engage as family or engage as school is not simple; it is constructed in multiple contexts, some of which are competing: personal, professional, social, and political. As such, what might appear to be (dis)engagement on the school landscape might be something completely different as viewed by a family; conversely, what might appear to be (dis)engagement to a family might be something completely different as viewed by a school.

Understanding who we are as family-school communities, what we believe, and why, is, therefore, critical. The project was, therefore, informed by Nodding's (1984) ethics of care, sociocultural theory (Greene \& Compton-Lilly, 2011; Rogoff, 1995; Vygotsky, 1978), and Freire's (1970/1998) notions of cultural action as reinforced by McKenna and Millen (2013). Noddings (1984) cites care and relationship within families, schools, and communities as not only an educational goal, but as a fundamental aspect of education. In her estimation, relationships should be ongoing, receptive, reciprocal, and motivated, all of which are facilitated through modelling, dialogue, practice, and validation of involved parties. Greene and Compton-Lilly (2011) as well as Vygotsky (1978) reminds that engagement perspectives and practices should recognize the ways in which these are related to social and cultural experiences. Greene and Compton-Lilly (2011) suggest that research teams consider both historical and contemporary policies as well as the discourses in schooling and society that both foster and impede family engagement; further they caution us to recognize that "parent involvement is always situated within power-laden relationships within schools, classrooms, and communities" and that "power operates as children's ... life experiences are either recognized or dismissed as they enter school" and begin formal instruction (p. 5).

Similarly, Freire (1970/1998) advocates for cultural and community action that is grounded in awareness of self and the world, aiming to recognize "society's internal and external contradictions" (p. 477). Such awareness of self and the role we play allows us to take a step back, examine our assumptions in context, and seek to include those who are silenced, marginalized, or alienated; essentially, those who might appear to be disengaged on the school landscape. Within the context of family-school engagement, we can apply Freire's (1970/1998) insistence that marginalized populaces, in this case the family, be recognized for their inherent value and nobility, as opposed to being taught how to fit the school-determined model of obedient, compliant, involved parents.

The objective is, therefore, to recognize family-school engagement that privileges parent voice and parent presence:

... parent voice is the right and opportunity for parents and caregivers to express their understandings about their child(ren)'s and families' everyday lives and educational experiences in and out of school. These expressions may consist of parents' desires, dreams, goals, and hopes for their families and children as well as frustration, concern, or anger over isolation and exclusion. Parent presence refers to a parent or caregiver's active involvement in their children's education, whether 
through formal school space (traditional activities) or "in more personal, informal spaces, including spaces created by parents themselves" (Carreón et al., 2005). (McKenna \& Millen, 2013, pp. 17-18)

\section{Choosing a Methodology of Empowerment and Equilibrium}

The methodology used throughout the project was consistent with valuing and empowering all parties, with the ultimate and collective purpose of supporting student, family, and school success and well-being.

\section{Participants}

Participating in the research were a total of four schools located in the Muskoka area of Ontario: one secondary school, which served the entire northern district of the board, and its three feeder elementary schools, all bound together by a vast geographical boundary that saw some students travelling up to one hour each direction to get to and from school. Collaborative inquiry (CI) teams were formed in each of the four schools, comprised of all family-school stakeholders: parents, administrators, teachers, and trustee. Each CI team was composed of one or two parents, typically representatives of the school council, one or two members of the academic staff, and the administrator of the school. Trustees, superintendants, coordinators, and Ministry staff joined the conversations at different times. Participants were recruited via school board invitation, first introduced at a principals' meeting and later distributed to the school community through a recruitment notice inviting all parties to participate.

\section{Methods}

Both collaborative inquiry and community-based research methods facilitated and guided the basis of discussions, which were scheduled every second month over the course of two academic years from 2013 to 2015 (supplemented by email and phone contact, as well as individual school visits and professional development). Sessions, typically a half day in length, built upon themes and key concepts established in previous conversations, slowly unpacking deeply held assumptions and enabling shifts of mindset, tonality, and respect between parties.

Collaborative inquiry $(\mathrm{CI})$ is the systematic reflective study of one's actions, and the effects of those actions within the context of a group that shares similar values and outcomes. It involves deep inquiry into one's professional practice (Riel, 2010). Community-based research (CBR) is defined as a partnership of equally invested stakeholders within a community who work collaboratively to address a collective issue (Strand, Marullo, Cutforth, Stoecker, \& Donohue, 2003), in this case, enhancing familyschool engagement.

Grounded in community dialogue, both CI and CBR offered a way for families, teachers, and administrators to confront and deconstruct the assumptions they (sub)consciously apply when working together (Pellerin, 2011). Cyclical and recursive in nature, $\mathrm{CI}$ and $\mathrm{CBR}$ enabled us to spiral with our teams through decisive action and subsequent reflection, before launching into renewed and redirected efforts. Throughout the process, data was collected and analyzed, policy was critically examined, and individual perspectives were shared.

After the culmination of the project, data in the form of transcripts, survey 
responses, school documents, brainstorming records, journals and field notes were printed, photocopied, and distributed amongst a team of three to comb for themes, ideas, commonalities and patterns. Each team member reviewed the data independently, before returning to the table to work collaboratively to identify and isolate principles that addressed key points that our data consistently pointed towards.

\section{Shifting the Balance: Moving from Edicts to Invitations}

As family-school teams began the project, it was with the knowledge that the parents who were participating as collaborators were already considered to be engaged (by both themselves and the school), and possessed positive working relationships with teacher and administration; interestingly, they too were frustrated by fellow parents who failed to match the mold and who were seemingly disengaged, sharing stories of low volunteer turnouts and attendance at school events.

Attendance at school-based events, quick returns of classroom forms, and easy accessibility via communication channels are certainly one of the simplest methods of gauging family engagement; however, beneath the surface, an undercurrent of personal, political, and socioeconomic factors are busily creating invisible barriers that invisibly set up hierarchies of privilege, authority, and power (Auerbach, 1989; Pushor, 2012). Although schools may work tirelessly to create school-based events that appeal to the broadest audience on a topic that the school feels is important, these events may ultimately be undermined by a legacy of negative narratives and judgment toward families. While the collaborative inquiry teams in our research projects were actively attempting to change the traditional school-centric approach to supporting families, they found themselves up against a longstanding widespread history of school communications that read like edicts, demanding family presence at school events, open house nights, and fundraising meetings, all while reminding families that family involvement was the single most predictor of student achievement.

Recognizing that schools had been perpetuating the myth of the good family based on visibility within the building, our CI teams concentrated their efforts on shifting their mindset and language to include and invite families on their own terms, thus attempting to set aside the myth of family (dis)engagement. In one notable example, the high school administration and IPRC team took their meetings to families in their own communities; given that some students traveled up to one and a half hours each way to attend the region's sole Catholic high school, the administration toured to meet with families to soften limitations of accessibility. This same high school adjusted their language from Meet the Teacher to Meet the Family and from Parent Involvement Committee to Family Engagement as well as combining many of their school events into one day or night session to reduce travel, weave in student showcase events, and minimize the time it would take away from the families' busy schedules. In addition to many other small adjustments to their school culture, the hanging of a permanent Welcome Parents! banner in their front foyer further solidified their proud, public desire to build meaningful relationships with families and the community.

Despite monumental efforts by the schools and CI teams, many seemed disappointed at the end of the process by the smaller-than-anticipated increase of family attendance at school events. For our high school team, family engagement had been viewed as a tool to increase enrolment and community visibility, and although their work had been 
effective, imaginative, and thoughtful, their recruitment did not swell to the degree that they'd hoped. We hastened to assure them that they were laying the groundwork for flourishing family relationships to come, that their seeds and roots needed time to establish themselves below the surface before bursting above the surface.

As researchers, we reminded family-school teams that documentation of growth is essential to charting progress; a plant typically grows slowly, so slowly that if they were to base expectations for its fruition based on one week's growth, they'd likely forecast a poor harvest. But if they documented the entire process, from beginning to end, they'd see the lifespan of its growth, and could perhaps trust that future seeds would also germinate and flourish. For the first time gardener of relationships, this process can be nerve-wracking. We encouraged our participants to stay the course, and not abandon their efforts once the research project was completed, understanding that the shift from edict to invitation would not immediately result in stampeding hordes of families desperate to enter the school and participate in meaningful conversations. Rather, the process is expected to be slow, and requires a great deal of patience from both parties as old barriers and resentments are carefully deconstructed and discarded.

\section{Essential Principles, Questions, Strategies}

There is no one size fits all approach to family-school engagement. Engaging families and engaging schools each exist within particular contexts that must be well understood in order to maximize ongoing, receptive, reciprocal, motivated, and respectful relationships that will ultimately give way to parent presence and parent voice (McKenna \& Millen, 2013). While there is no concrete recipe, we do offer a set of generalized principles (see Figure 1) generated by our family-school teams as a way to enhance family-school engagement and render families and schools mutually accessible.

Given our focus on family-school (dis)engagement as a diverse, responsive, set of beliefs and practices, we offer multiple ways of viewing these principles: a) opening anecdotes present a short description of what we observed and experienced in the field; $b$ ) key questions are those we asked of ourselves as well as those generated by our CI teams; and lastly c) evidence-based strategies are listed, grounded in both theory and practice. These principles are not intended to be addressed sequentially, or used as a checklist. Like relationships, they are ongoing practices that require continual revision as the contexts of families and schools continue to change and evolve. Instead, we offer these as a means to facilitate discussion, assess current climate, and plan meaningful and authentic ways forward.

Set the stage, create a welcoming environment

Know your families, understand your context

Grow trust, build community

Suspend judgment

Check assumptions

Do differently, not more

Communicate with purpose

Assess confidently

Figure 1. Essential principles for family-school engagement 


\section{Set the Stage, Create a Welcoming Environment}

Aesthetically pleasing and welcoming environments show families how they belong. Our participating secondary school timed an outdoor art project to coincide with the annual barbecue that welcomed both students and families back to school. Using highgrade artist's quality street chalk, the art classes created a dynamic, colourful, eye-catching display on the entrance walkway to the school. The result was impressive; students felt valued for their artistic contributions, and parents could interact with not only their child's work, but the entire class's efforts. By aligning school practice to support and encourage student and family pride, the secondary school reaped the reward of incredibly positive community feedback that bolstered spirits and improved relationships.

Similarly, each elementary feeder school developed their own take on a unified theme; the family tree. Some trees were seasonal, and featured names and photographs of family members of students on each leaf. Others were made a permanent fixture by painting them directly onto the bricks. Regardless of what form it took, the school's unique family trees invited students to proudly show their families, and gave families an activity to do with their child immediately upon arrival into the school (finding their leaf on the massive tree). The trees bound the elementary schools together with a common thread; if the students choose to go on to the secondary school, eventually they will each have experienced the celebration of their unique family contexts through a tree.

Questions: What can we do to foster safe, warm, and welcoming family-school communities?

What does this mean for school staff, school council, students, and families?

Does it look and sound the same for all?

Strategies: Lead by example: create safe spaces for people to ask questions and offer thoughts and opinions.

Create a warm and visually appealing entry space: construct a family-school tree that represents all.

Facilitate family-to-family connections: lead off formal activities with an informal social that puts families in touch with one another.

Plan a family challenge that builds community and engages all families.

\section{Know your Families, Understand your Context}

Our participating secondary school boasted unique culinary and hospitality programming that set it apart from local high schools. An offhand comment by one parent, who mentioned that she was a professional cake decorator, turned into a special workshop for the hospitality students, led by the parent. Accessing the family community's funds of knowledge (González \& Moll, 2005; Moll, Amanti, Neff, \& González, 1992) led to a richer resource base and fantastic learning opportunities for students and teachers alike. Capitalizing upon the strength of families, students, and staff alike led to meaningful, exciting, and engaging interactions between all parties, resulting in a positive, welcoming culture of learning.

The elementary schools examined common areas of anxiety for families, and settled upon homework (a term that we attempted to problematize - should it not be home practice 
or home fun as opposed to homework?), specifically math, and hosted a themed Math Extravaganza Night. The event was brainstormed, created and executed by a joint team of parents, staff, and the family council. The school that took the lead on the project saw high turnout and strongly encouraged other schools to attempt a similar night. Their approach was imaginative and exciting for parents, students, and teachers alike; families were invited to go to outer space, and all of the math activities, decorations, and layout were astronomically inspired. By providing an event that was meaningful for all parties, the school served its constituency through creating a collaborative learning environment in which teachers, families and children could play and explore together while deconstructing commonplace cultural anxieties surrounding math and homework.

Questions: How do we get to know our family-school communities?

What is the role of families in our community?

What is the current nature of our family-school relationships, and school climate?

How do we understand the aspirations and goals of families and schools?

How do we support families in an increasingly busy world?

Strategies: Use storytelling and story listening to learn about families (in multiple languages,

images, or concrete objects). Share your story as a stimulus.

Invite an All About Me page, a family sharing of gifts, a collage.

Host a Silent Auction where families contribute a particular talent (e.g., cake decorating, card making).

Be aware of the community context of your family-school community.

Be aware of out-of-school family commitments.

\section{Grow Trust, Build Community}

As educators, it is more likely than not that we had mostly positive experiences in our own schooling, steering us back into the system as teachers. Parents who meet the traditional definition of engaged are typically comfortable enough within the school walls to participate and interact with educators and administrators; whereas families who are labeled as disengaged may have had a negative experience with schooling or with a teacher in the past. Our teams worked diligently to overcome their own high expectations of being able to win over each and every family regardless of past experience; we all reminded ourselves that meaningful change does not occur overnight, and that trust is a delicate, long-term project requiring constant maintenance, upkeep, and care.

Though many in our CI teams expressed a desire to see more tangible results, which were frequently conflated with new enrolment numbers in the school, we reminded ourselves and our participants that trust takes time to build, and community growth requires a solid foundation. We recognized that it was incumbent upon us to exercise patience, understanding, and vulnerability, and each school learned to celebrate small victories, such as a higher-than-normal turnout at a special event. Getting to know families and strengthening the home-school connection takes time, careful analysis, and of course, some trial and error to find the ideal methodologies and activities to serve, empower, and engage families. The establishment of a parent resource library in the front lobbies of our 
participating schools was a small, yet visible and ongoing, demonstration of each school's commitment to trusting families; families were allowed to take what they needed and to return the resource when they were finished, no questions asked, no judgment passed.

Questions: How do you grow trust with your families at the district level, school level, class level?

How do you create open and safe spaces for families to ask questions, share stories, and express opinions?

How can we restore the trust of teachers and families who have experienced educational distress?

Strategies: Recognize that trust is action-oriented and requires ongoing attention and risk-taking on the part of families and schools

Don't give up on families; recognize negative narratives and work toward positive alternatives

Share stories of success and struggle

Recognize that it's the little things that make the greatest difference: celebration of difference, multiple ways to do the same activity

\section{Suspend Judgment}

In a moment of total candor, one of our parent CI team members reflected that perhaps she set the bar for parent engagement to an impossible to attain level; as both the chair of the parent council and tireless volunteer, she expected the same level of commitment to school-based activities from other families. In recognizing that her own definition of engagement placed unfair and unrealistic expectations upon other families, our participant gave voice to the suspension of judgment that must occur in order for meaningful relationships and trust to be (re)established between parents, students and schools.

All of our CI team members recognized the demands that the contemporary family faces; each parent may balance multiple jobs, each child may juggle multiple extracurricular activities on top of their schooling, and school-based events may conflict or take lower priority on the family calendar. The mere fact that children make it to school on time every day may in fact require monumental, yet invisible effort on the family's behalf; these struggles are not always public due to the stigma placed on lower socioeconomic status and/or single-caregiver families. Transportation may prevent some families from attending school events, while others may not have the money to submit to teachers for field trips, leading the teacher to erroneously believe the parents simply do not care about their child or about their child's education.

Questions: What is the most difficult conversation or situation you can imagine?

What are the possible risks? What are the possible gains?

Is there such a thing as too much or too little engagement?

How can we suspend judgment, and tread carefully into conversations and leave all involved feeling valued, respected, and honoured (including ourselves)? 
Strategies: Recognize that many families perceive judgment based on past, often negative experiences.

Don't jump to conclusions.

Listen with your heart as well as your ears - hear what is being said and what is not being said.

Offer reassurance: share a story, make a connection; provide an example when you felt the same. Foster the belief that, "We are all this together."

Communicate often and well - plan the interaction and anticipate positive and negative responses.

Be real and authentic.

\section{Check Assumptions}

Working through many of their assumptions gave our CI teams the opportunity to explore safe-space communication, in which each member of the team could voice the perspective of their role as caregiver, teacher, or administrator. Active listening became common practice at our meetings, with each participant carefully considering and listening not only with their minds, but empathetically through their hearts. We strongly recommend this strategy as a place to begin with the suspension of judgment and deconstruction of assumptions; regardless of who possesses the preconceived notion of family-school relationships, active listening provided our CI team the opportunity to change their thoughts and their hearts.

This shift was reflected in a conscious, subtle alteration of language and tone; frustration was replaced with thoughtful questioning and probing, seeking answers instead of fanning flames. Our participating schools took responsibility for changing their institutional mindset and successfully adjusted their culture to be less judgmental and more accepting. Communication strategies were diversified, amplified, and adjusted to be more respectful to families. All of the schools switched from an automated voice system to a guaranteed pick-up by a staff member; if the secretaries were unavailable, the calls would be directed to administration. Our participating educators reported that when encountering families, they would intentionally listen more and speak less, reminding themselves constantly that there was an unseen and unheard story behind previous assumptions, and that understanding families could unlock a new, positive relationship.

Questions: How does our use of language or print text privilege or marginalize some families?

What are our goals of family-school engagement (e.g., are we trying to teach families?)?

What assumptions do families and schools bring to the table?

How do engagement strategies reflect these assumptions?

Strategies: Talk less, listen more - not only with our ears, but our hearts as well.

Explore from multiple perspectives.

Lead by example: create safe spaces for people to ask questions and offer thoughts and opinions.

Create a warm and visually appealing entry space: construct a family-school tree that represents all. 
Facilitate family to family connections: lead off formal activities with an informal social that puts families in touch with one another.

Plan a family challenge that builds community and engages all families.

\section{Do Differently, Not More}

As previously discussed, the contemporary family faces additional pressures and choices for how to spend their time outside of school. For families with multiple children, each night may present a labyrinthine schedule of commitments, such as hockey, piano, dance and tutoring. Similarly, teachers must meet their professional demands - planning units, recording assessment and evaluation, communicating with families - while perhaps shouldering extracurricular school activities as volunteer work, such as running the school robotics team or coaching basketball. Many teachers also have children of their own, and know all too well the stressful reality of keeping up with their own children's activities. As a result, successful parent engagement may seem like yet another demand upon everyone's already limited free time.

Our CI teams discovered through coaching and their own anecdotal experience that positive family-school engagement may in fact simply require a different approach, rather than heaping more responsibility upon families, educators and administrators. Homework was re-envisioned as an opportunity for students to engage with their families, then return to school with new experiences to share; students were invited to explore family literacy through nature walks, family artifacts, and family stories. Several schools provided conversation prompts, to help caregivers overcome the typical answer to "what did you do at school today?" ("Nothing!"). Events held at the school were collated onto the same day, to ease travel pains for families who had to go out of their way; similarly, these events placed an emphasis on student talent, such as Coffee Houses and Talent Nights, to entice parents to come and experience firsthand the shift in culture that the schools worked hard to attain.

Questions: How do we envision family-school engagement?

Are children and youth part of the equation?

Do we recognize competing priorities of family, school, society?

Is our focus to teach, to support, or to engage?

Strategies: Recognize children and youth as active, legitimate, and equal partners.

Support families as they come to understand out-of-school engagement (e.g., mealtime conversations, walks to the park, fishing).

Focus on homework as inspired family-school practice

Plan school activities that engage families in meaningful interaction and exploration with their children (e.g., real life math, Family Talents, Coffee House).

Make conscious choices that build partnership, welcome families, and celebrate differences

Plan for multiple layers of engagement

Recognize that many families find homework intimidating 


\section{Communicate with Purpose}

Communication was consistently identified as an area in which both families and schools needed to focus. Philosophically, we asked our CI teams to understand the purpose of communication; were we sending home something that really mattered? Were educators as receptive to communications stemming from the families? Were schools willing to adjust their communication channels, frequency, and style based on family feedback? Were teachers just as willing to make efforts to communicate student successes as they were to complain about student struggles? These questions guided our efforts to generate a menu of options that helped our CI teams improve home-school communications.

One of our teacher participants demonstrated the success she had had with a smartphone application; the program allowed her to text updates and reminders to family, without the recipient being able to see her personal cell phone number or respond directly. Although by definition it was purely one-way communication, she saw an increase of returned forms, and families remained informed of important upcoming tests and project deadlines. Our other participating schools picked up the application, and experienced similar, positive results.

Another form of meaningful communication that is utilized board-wide is the threeway conference; students, families, and teachers are invited to sit at the table together, while the student leads a presentation on their own progress. Just as the showcase of youth artwork drew families into a warm, welcoming school environment, student-led initiative and communication via three-way conference is a positive, successful strategy for homeschool partnership that the board has integrated for years. Our CI teams renewed their dedication to allowing families and children the right to speak first, to voice their concerns, questions, and ideas to a teacher who is sitting patiently with open ears and heart. In a blog post on the subject, we also advised that educators refrain from communicating laundry lists of issues that their students are having; we advise that at conferences, teachers prioritize one or two areas of development to target collaboratively with families and students. By encouraging meaningful, exploratory discussions on a prioritized area of focus, rather than attempting to correct an overwhelming amount of issues, all parties are given the opportunity to plan, strategize, and move forward.

Questions: How do families and schools communicate?

How do we support both families and schools to communicate with confidence?

What is the purpose of communication?

Do you value child/family knowledge by asking for critical information and feedback?

Strategies: Communicate your knowledge of the child

Problem solve with families - find a collaborative solution

Develop a plan that facilitates communication

Differentiate when necessary

Adopt a 24 hour rule

Involve children/youth - hold three-way conferences

Ask questions instead of making assumptions

Follow up when necessary 
Keep it positive - try a for good /for bad or good news/bad news approach

\section{Assess Confidently}

Throughout the project, assessment was perhaps the area we struggled the most with, as is evident throughout our discussion. Our CI teams tended to rely on preset indicators - increased attendance at school functions, enhanced communication, greater enrolment - which are quantifiable, and relatively easy to measure. We learned, although it was a difficult lesson, that our measures of family-school engagement are grounded in our goals, assumptions, beliefs, and practices, all of which are hard to change and even more difficult to measure. We found that it was critical, particularly when encouraging our teams to continue the work they were doing beyond the scope of the research project, to separate our definition of success from quantitative data and focus instead on the shifts towards a friendlier, more inclusive landscape. Whether these adjustments were visually evident, such as the banners, families trees, and lending libraries, or were simply palpable through a sense of harmonious, re-established connections with families, we challenged our participants to think of the impact their work had had beyond the numbers; instead, we asked them to witness the impact within the hearts and minds of the members of the school community.

Questions: How do we measure success? What is success?

Is it fair to count participation, homework completed, student achievement? If not these indicators, then what?

What purpose does assessment and measurement serve?

To whom are we accountable?

Strategies: Assess how you are doing by asking the right questions: What is the most important thing to do in terms of family-school engagement? How do we know what to do first? When is the most important time? What is not to be missed? Who are the most important people, the ones I should listen to before all else, within the context of family-school engagement?

Conduct a survey: ask often, "How are you engaged? How would you like to be engaged? How are we doing? How can we improve?

Know your family-school community well - select relevant measures (e.g., How long do they linger after the event has concluded?)

\section{Concluding Remarks: Getting From Where We Are to Where We Could Be}

Over the years, and today in retrospect, we've come to understand that families do the best that they with the resources they have in any given moment; they make decisions in the best interests of their families and children, and sometimes that means that they reject the school knows best narrative, privileging instead what they know best - their children. Like Day (2013), we've come to understand that we must accept families' terms of engagement and meet them where they are with empathy, sensitivity, responsiveness, flexibility, appreciation, and respect. This is something that we now encourage of our family-school teams who are working to enhance engagement in a variety of ways. Regardless of whether we are teacher, researcher, even parent educator, we need to recognize that our "perceptions of parental involvement are, more often than not, situated 
in good faith and stem from well-meaning intentions but can misconstrue what many parents' expectations, participation, love, and care for their children look and feel like on a daily basis (McKenna \& Millen, 2013, p. 10). If, however, "we listen closely to parentstheir wishes and dreams, fears and concerns-we find that there are lessons and suggestions that emanate from a deep sense of caring" (McKenna \& Millen, 2013, p. 10).

\section{References}

Auerbach, S. (2010). Beyond coffee with the principal: Toward leadership for authentic school-family partnerships. Journal of School Leadership, 20(6), 728-757.

Day, S, (2013). "Terms of engagement" not "hard to reach parents." Educational Psychology in Practice, 29(1), 36-53.

Freire, P. (1970/1998). Cultural action for freedom: Author's introduction. Harvard Educational Review, 68(4), 480-522.

González, N., Moll, L., \& Amanti, C. (Eds.). (2005). Funds of knowledge: Theorizing practices in households, communities and classrooms. Mahwah, NJ: Erlbaum.

Greene, S., \& Compton-Lilly, C. (2011). Introduction. In C. Compton-Lilly \& S. Greene. Bedtime stories and book reports: Connecting parent involvement and family literacy (pp. 1-9). New York, NY: Teachers College Press.

McKenna, M. K., \& Millen, J. (2013). Look! Listen! Learn! Parent narratives and grounded theory models of parent voice, presence, and engagement in K-12 education. School Community Journal, 23(1), 9-48.

Moll, L. C., Amanti, C., Neff, D., \& González, N. (1992). Funds of knowledge for teaching: Using a qualitative approach to connect homes and classrooms. Theory Into Practice, 31(1), 132-41.

Noddings, N. (1984). Caring: A feminine approach to ethics and moral education. Berkeley, CA: University of California Press.

Pellerin, M. (2011). University-school collaborative action research as an alternative model for professional development through AISI, Retrieved from http://www.uleth.ca/education/sites/education/files/AISI\%20V1\%201\%201\%20F all\%202011.pdf

Pushor, D. (2011). Looking out, looking in. Educational Leadership, 69(1), 65-68. Retrieved from: http://www.ascd.org.roxy.nipissingu.ca/publications/educationalleadership/sept11/vol69/num01/abstract.aspx

Pushor, D. (2012). Tracing my research on parent engagement: Working to interrupt the story of school as protectorate. Action In Teacher Education, 34(5-6), 464-479.

Retrieved from: http://dx.doi.org.roxy.nipissingu.ca/10.1080/01626620.2012.729474

Ramirez, A. Y. (2004). PASSport to success: An examination of a parent education program. School Community Journal, 14 (2), 131-152. Retrieved from http://www.schoolcommunitynetwork.org/SCJ.aspx

Riel, M. (2010). Understanding action research. Retrieved July 2013, from http://cadres.pepperdine.edu/ccar/define.html

Rogoff, B. (1995) Observing sociocultural activity on three planes: participatory appropriation, guided participation, and apprenticeship, In Wertsch, J. V., del Rio, P. \& Alvarez, A. (Eds.). Sociocultural studies of mind. (pp. 139-164) New York: 
Cambridge University Press. Retrieved June 25, 2012 from

http://methodenpool.uni-

koeln.de/situierteslernen/Teaching\%20As\%20Learning.htm

Strand, K., Marullo, S., Cutforth, N., Stoecker, R., \& Donohue, P. (Eds.). (2003).

Community-based research and higher education: Principles and practice. San Francisco: Jossey-Bass Publishers.

Vygotsky, L. (1978). Mind in society. Cambridge, MA: Harvard University Press.

\section{Author Biographies}

Michelann Parr, PhD, is professor at the Schulich School of Education at Nipissing University in North Bay, Ontario. Her research interests include family-school engagement and well-being, text-to-speech technology and its impact on the reading process, and writing as a way of fostering teacher-candidate understanding.

Marianne Vander Dussen is a recent graduate of the Master of Education program at the Schulich School of Education, Nipissing University. She is a recipient of the Dave Marshall Leadership Award, and currently works as both a teacher in her local school board and as an independent art instructor in the community. 